\title{
DINAMIZACIÓN DEL PATRIMONIO LITERARIO: USOS CULTURALES DE LA LEYENDA* \\ DYNAMIZATION OF THE LITERARY HERITAGE: CULTURAL USES OF THE LEGEND
}

\author{
Pilar Vega Rodríguez \\ Universidad Complutense de Madrid
}

\begin{abstract}
RESUMEN
A partir de la investigación del proyecto DLLHO_19, este trabajo reflexiona sobre el valor patrimonial de la leyenda (oral o literaria) y sobre los usos culturales que pueden colaborar a la conservación y dinamización de este activo, junto con la trascendencia del legendario en las investigaciones sobre geografía literaria.
\end{abstract}

PALABRAS CLAVE: patrimonio literario, leyenda, usos culturales, geografía literaria.

\section{ABSTRACT}

Based on the research project DLLHO_19, in this paper we reflect on the heritage value of the legend (oral or literary) and on the cultural uses that can contribute to the conservation and dynamization of this asset, together with the transcendence of the legendary in the investigations on literary geography. KEY WORDS: literary heritage, legend, cultural uses, literary geography.

1. El patrimonio lo constituyen el conjunto de bienes materiales ${ }^{1}$ que en continua interacción constituyen el activo a través del cual un pueblo participa en el devenir de la Humanidad. Este acervo lo integran expresiones materiales (muebles e inmuebles), e inmateriales (instrumentales, éticas, religiosas, artísticas, lingüísticas,

* Recibido: 03-03-2019 / Aceptado: 18-09-2019.

${ }^{1}$ El patrimonio material o tangible se compone de objetos físicos o artefactos que el ser humano construye (herramientas, utensilios u objetos artísticos); a estas dos categorías se añaden los sociofactos, o comportamientos, ritos y costumbres que la gente practica para regular sus vidas. indistintamente patrimonio intangible o inmaterial, para significar «los usos, representaciones y expresiones, así como el conocimiento y las habilidades necesarios asociados que las comunidades, grupos y, en algunos casos, los individuos reconocen como parte de su patrimonio cultural»; Cfr. UNESCO Convención para la salvaguarda del Patrimonio cultural inmaterial, (2004). Disponible en: http://portal.unesco.org 
políticas, sociales, económicas, culturales, etc.). Forman parte de este patrimonio no sólo las expresiones cristalizadas de una cultura (objetos antiguos, arquitectura, sitios arqueológicos, textos literarios) sino también otros bienes no tangibles o inmateriales, como las tradiciones ligadas a un territorio, prácticas culturales, relatos, etc. e incluso conceptos de cierta abstracción, como los de identidad, nacionalidad.

Se trata de un capital recibido de las generaciones precedentes que las que nos sucederán tienen derecho a recibir; esto implica en el patrimonio una movilidad continua entre lo legado y lo transmitido. De modo que el patrimonio, siempre en constante evolución, arrastra consigo los diversos modos de vida y de mentalidad por los que una sociedad atraviesa y lo constituyen tanto los productos del pasado como los actuales (nuevas artesanías, lenguas, conocimientos ${ }^{2}$ ), en cuanto bienes que pueden ser rememorados y recreados por la sociedad para su progreso ${ }^{3}$.

La trayectoria del cuidado del patrimonio ha sido principalmente conservacionista. Dado que la memoria de las comunidades tiene una subsistencia corta, ligada a la visibilidad de los hitos que permiten el recuerdo, el patrimonio cultural necesita de la intervención coordinada de agentes privados y públicos para hacer perdurable la visibilidad y memoria de sus bienes ${ }^{4}$. Algunas de estas acciones son el sostenimiento de la investigación arqueológica, la creación de museos, de centros históricos de interpretación, las publicaciones, la organización de eventos culturales, la difusión cultural masiva, etc. Como resultado de estas acciones, se produce la democratización de la cultura, se logra la incorporación de los símbolos a la memoria colectiva, y la identidad de grupo resulta cohesionada. Esta sería la perspectiva conservacionista del patrimonio en la que intervienen principalmente sectores profesionales (historiadores, arqueólogos, arquitectos, restauradores, etc.).

Es inevitable que en el criterio de lo que debe conservarse o restaurarse del patrimonio cultural intervengan factores muy diversos (económicos, sociales, simbólicos, incluso políticos) y que en las motivaciones de los agentes de la conservación del patrimonio puedan intervenir razones ideológicas o mercantilistas; pero, a la vez,

${ }^{2}$ «El patrimonio cultural de un pueblo comprende las obras de sus artistas, arquitectos, músicos, escritores y sabios, así como las creaciones anónimas, surgidas del alma popular, y el conjunto de valores que dan un sentido a la vida. Es decir, las obras materiales y no materiales que expresan la creatividad de ese pueblo: la lengua, los ritos, las creencias, los lugares y monumentos históricos, la literatura, las obras de arte y los archivos y bibliotecas». DEFINICION, Patrimonio Cultural de la UNESCO México 1982.

${ }^{3}$ N. García Canclini, «Los usos sociales del Patrimonio Cultural», en Aguilar Criado, Encarnación, Patrimonio Etnológico, Nuevas perspectivas de Estudio. Consejería de Cultura, Junta de Andalucía, 1999, pp. 16-33.

${ }^{4}$ Este patrimonio puede pertenecer a la propiedad pública o privada pero su preservación y conservación es responsabilidad de todos, sea cual sea su propietario (el Estado, las instituciones competentes, todos los ciudadanos). 
es innegable que en muchas ocasiones solo el respaldo de las instituciones consolidadas consigue frenar el saqueo especulativo y promueve acciones de recuperación y conservación.

Pero la perfecta conservación de un patrimonio solo es posible por la simultánea dinamización, muy especialmente en el caso del patrimonio inmaterial que, si se convierte en un ámbito de la rareza y deja de pertenecer a todos, pierde su condición de patrimonio. Dinamizar el patrimonio cultural supone llevarlo más allá del ámbito del experto (de los historiadores, arqueólogos, etc.) de forma que su significado pueda continuar siendo utilizado y comprendido (en el ámbito del turismo, el desarrollo urbano, la comunicación etc.). Para ello, es imprescindible no solo la formación de la sociedad en el cuidado y promoción del patrimonio sino la realidad de un uso cultural de ese patrimonio. En la medida en que la memoria y la valoración social custodian el patrimonio es posible continuar generándolo y acrecentándolo, que es el modo óptimo de conservarlo. Esto requiere consensuar y emprender labores de reconstrucción y/o recreación de elementos emblemáticos dañados o desaparecidos, y simultáneamente seguir incorporando nuevos elementos a la red patrimonial. «El patrimonio es algo vivo. Sólo las sociedades vivas son capaces de crear patrimonio ${ }^{5} \gg$.

Desde esta perspectiva dinámica el patrimonio es un instrumento del desarrollo y la difusión cultural cuyos usos sociales conviene estudiar.

2. Cada vez más, el patrimonio literario es considerado fuente de valor económico para las sociedades, no solo por su capacidad de transformarse en negocio o producto (el editorial, por ejemplo) sino también, por su actuación como factor productivo en los planes de desarrollo y dinamización del turismo cultural, con nuevos usos posibles.

Este patrimonio lo integran todas las manifestaciones artísticas del lenguaje que expresan el mundo humano. El patrimonio literario es simultáneamente material (textos producidos en un soporte físico y lugares físicos implicados por estos textos) e inmaterial (toda la carga de significación que implica un texto en ámbitos sociales, artísticos, culturales, políticos). Además, el patrimonio literario puede incluir manifestaciones intangibles, sin soporte, dependientes en exclusivo de la transmisión y memoria (es el caso de todas las manifestaciones de la literatura oral).

Tanto uno como otro requieren de la custodia y protección de las instituciones, que cooperarán con la iniciativa y trabajo personal de investigadores para la recuperación de textos, restitución de versiones, localización de atribuciones, catalogación

\footnotetext{
${ }^{5}$ C. Martínez Garate \& H. A. Ayerra, Conferencia Patrimonio: ¿un concepto en crisis?, España, 2006. Disponible en: http/ /:www.nabarralde.com [Consultado: marzo 2006]
} 
y conservación de legados literarios, etc. En esta tarea intervienen los conservadores, historiadores, bibliófilos y bibliotecarios, filólogos, traductores, y también, políticos, educadores, gestores culturales, quienes trazan estrategias para la perduración del patrimonio en la conciencia e identidad social.

El patrimonio literario acoge también, más allá de la obra literaria de los escritores, los espacios vinculados a esa obra (casas del autor, rutas literarias de personajes / temas / biografías, lugares monumentales ligados a los textos literarios, etc) ${ }^{6}$.

Entre los bienes del patrimonio literario inmaterial se cuentan los relatos tradicionales en su soporte oral, las leyendas, vinculadas en tantos casos a un espacio geográfico o a un objeto que puede generar glosa o ficcionalización. En este caso, y en muchos otros, el texto del patrimonio literario potencia el valor del patrimonio territorial o material (como objetos significativos) a los que aporta significados históricos o simbólicos. Por eso el territorio puede convertirse con frecuencia en un recurso cultural, literario y económico de gran importancia ${ }^{7}$. Se entiende así que la revalorización de paisajes haya alcanzado trascendencia como riqueza patrimonial de las sociedades, más aún cuando es posible interpretar o resignificar esos espacios ${ }^{8}$. Ocurre esto cuando se explican y detallan sus circunstancias particulares (su historia, tradiciones, condiciones), y cuando ese espacio continúa siendo vivido y comprendido. ${ }^{9}$ Podríamos denominar estos espacios entonces como «lugares literarios».

Son lugares literarios, además de aquellos en los que nació, vivió, escribió y murió un escritor o el lugar donde está enterrado, su casa (musealizada), o los lugares por donde han deambulado sus personajes, también los sitios en los que escriben o viven los autores coetáneos, , los pueblos y ciudades, tal como los contempla la literatura sin olvidar los lugares imaginarios, y los lugares descritos en las guías de viajes como ligados a personajes, hechos históricos, hitos geográficos y monumentales de los que

\footnotetext{
${ }^{6}$ A. Bataller Catalá, «La ruta literaria como actividad universitaria vinculada al territorio y al patrimonio». Disponible en: https://www.uv.es/asabranca/encontre/bataller.pdf [Consultado: 23-12-2018].

7 J. Ortega Valcárcel, «El patrimonio territorial: el territorio como recurso cultural y económico», Ciudades, 04 (1998), pp. 31-48.

${ }^{8}$ R. Silva y Fernández y V. Fernández Salinas, «El patrimonio y el territorio como activos para el desarrollo desde la perspectiva del ocio y del turismo», Investigaciones Geográficas, nº. 46, mayo-agosto (2008), pp. 69-88.

${ }^{9}$ R. Dosso, «Paisaje, turismo y desarrollo. Contribuciones conceptuales para un desarrollo sustentable», Conferencia en Montevideo, 2010.
} 
se ha ocupado la literatura ${ }^{10}$. Estos lugares pueden vincularse entre sí conformando rutas o itinerarios, una posibilidad de interés creciente para el turismo cultural ${ }^{11}$.

3. Como se ha dicho, el patrimonio territorial se encuentra íntimamente vinculado con intangibles como la noción de «identidad», o «nación». En el mismo sentido, la leyenda, participa plenamente tanto del patrimonio territorial como del patrimonio inmaterial (en su soporte oral), y en el caso de la leyenda literaria de la objetivación material. Al igual que otros elementos del patrimonio intangible interviene en la generación de la identidad ofreciendo historias arquetípicas que van evolucionando y son revisitadas por los diferentes autores y públicos, en diferentes épocas, brindando una creación comunitaria. Son muy numerosas las leyendas fundacionales y etiológicas en las que se explica el origen y proceso de constitución de las identidades nacionales o territoriales.

Además de los mapas, estudios, y obras de restauración, etc. la persistencia del recuerdo de lo ocurrido en un espacio permite transformar los hitos visibles del pasado en un lugar de sedimento de memoria histórica. En este proceso interviene, como es lógico, la construcción imaginativa, a consecuencia de una evocación emocional y una perspectiva: «Este carácter subjetivo entronca con la cultura, con la geografía cultural, desde la que no solo nos preocupa el paisaje observado, sino también el que ha sido reflejado en diversos textos procedentes de la literatura (descripción, ficción, simbología $\left.{ }^{12}\right) »$.

La leyenda es ese tipo de historia que despierta una emoción admirativa; un texto que apela directamente a la vivencia emocional de los espacios a los cuales confirma como especialmente perfectos, sublimes, notables, llenos de significado, una emoción radicalmente positiva y placentera, que interesa y sorprende. No puede encontrarse, en efecto, algo más adecuado para la promoción de un espacio, mejor dispuesto a introducir al turista en esa experiencia emocional del pasado. Por tanto, la leyenda, al dar cohesión al territorio, y contribuir al dibujo de su geografía cultural,

\footnotetext{
${ }^{10}$ L. Soldevila, «Geografia literària dels països catalans: la gènesi d'un projecte'a», Literatura i paisatge, Tarragona, APELLC, 2009, pp. 12-13.

${ }^{11}$ Cfr. J. Camps y M. Viladegut, «Les rutes literàries com a introducció a la geografia artística dels escriptors», en Jornada sobre Literatura i Ensenyament, 2009.

${ }^{12}$ Cfr. F. Pillet Capdepón, «El paisaje literario y su relación con el turismo cultural», Cuadernos de turismo, (33), 2014, p. 300. Son referencias imprescindibles para esa visión emocional del paisaje y la comprensión de la geografía las obras de J. Bonnemaison - J. Lasseur y C. Thibault, La Géographie culturelle: cours de l'université Paris IV-Sorbonne 1994-1999, 2000; M. Brosseau, «Entre géographie et littérature: frontières et perspectives dialogiques», Recherches sociographiques, 44 (3), 2003, pp. 525-547; M. Crang y N. J. Thrift (eds.). Thinking space (Vol. 9), Psychology Press, 2000 y D. Mitchell, Cultural geography: A critical introduction, Blackwell, 2000.
} 
interviene de modo directo en la conformación del magma de significaciones de un entorno cultural ${ }^{13}$.

Ya que todo lo que se coloca en forma de narración se recuerda y persuade mucho mejor, las estructuras narrativas se han convertido en el fundamento de la actividad cultural en todas partes (la publicidad, el folklore, las artes plásticas, etc.). Independientemente del subsistema de que procedan, todas coinciden en lo mismo, la narración de una historia. La narración organiza la experiencia humana, le confiere una dirección y secuencia y, por tanto, una interpretación o explicación de una causa. El protagonista de la narración es siempre el sujeto humano, también cuando los personajes no lo son; cualquier protagonista de un relato asume la intencionalidad sólo propia del ser humano para mostrar una conducta, a través de la mediación del narrador.

Como en toda narración, el narrador de la leyenda selecciona hechos, los aglutina y organiza en función de una trama y desenlace. El material de que parte no es ilimitado, sin embargo; el relato arranca de otro relato previo, el cual puede ser moldeado y reescrito, siempre conjugando dos perspectivas temporales, la de un pasado no completamente fabuloso, en el que ocurrieron los hechos, y la interacción con el presente en el que el público puede cotejar la nueva versión ofrecida de un sustrato narrativo ya conocido. La relación del público / lector de la leyenda en relación al relato es diversa a la de un lector común, que no aplica ningún tipo de control al relato salvo el de las normas fundamentales de la verosimilitud.

La leyenda narrativiza el pasado, y con ello consigue tres objetivos. En primer lugar, una enseñanza moral, nunca mejor dispensada que a través del relato; en segundo, la conducción del receptor hacia el conocimiento propio, puesto que impone por fuerza la inexorabilidad del tiempo que pasa (recibir la historia es poder contrastarla con el estado presente del lugar visitado y de uno mismo). Finalmente, y por su propio dinamismo, los relatos asociados al lugar pueden suscitar nuevos relatos, ya que quien escucha una leyenda podrá reproducirla con amplificaciones o limitaciones, derivadas de su propia singularidad; ese ha sido el proceso de desarrollo y crecimiento habitual de todas las leyendas. La leyenda referida es semilla de nuevas narraciones y reescrituras, de nuevas fabulaciones, actualizadas según los contextos de producción y recepción. Todo narrador de lo legendario ha sido previamente receptor, y todo receptor puede convertirse en un futuro narrador; de ambos depende la continuidad de la memoria.

\footnotetext{
${ }^{13}$ Para el tratamiento de la leyenda como patrimonio territorial puede consultarse E. Martos Núñez y A. E. Martos García, «Las leyendas regionales como intangibles territoriales», 2015.
} 
Por otra parte, la leyenda es el fruto de una recepción y transmisión comunitaria en función de lo juzgado patrimonial en un momento dado. Pero la leyenda en la que es posible señalar un autor por haber recibido un tratamiento literario el análisis de los estratos patrimoniales es incluso más interesante ya que al intangible (temas, conceptos, cadena de transmisión) se añade el material del texto escrito, de autoría individual, pero generalmente no único. Las versiones e interpretaciones que la leyenda literaria realiza sobre la tradición popular son muy diferentes según las épocas, los estilos estéticos, los autores, de manera que la multiplicación de textos es obra de la preexistencia de intangibles culturales.

4. De lo dicho hasta ahora es fácil deducir la vinculación del patrimonio literario y los estudios de la geografía literaria, cuyo objetivo es la indagación en el diálogo semiótico que se entabla entre literatura, territorio y espacios culturales. La geografía fija el espacio, lo llena de significado, lo transforma en función de una perspectiva, posibilita el recorrido por él. En cuanto esta lectura se realiza desde el sentido de la pertenencia, desde una perspectiva subjetiva y emocional, es lógica la coincidencia ${ }^{14}$ entre literatura y geografía.

Con sus derivaciones en el campo de la «geocultura» y la «geo-poética» la geografía literaria ha promovido el estudio de las representaciones literarias de los espacios (ciudades, paisajes, territorios sociales y políticos), y a la inversa, la lectura literaria de espacios-ya sean reales, paisajes singulares o sitios culturales, obien poéticos, míticos, hasta ficticios- así como de las implicaciones que estas lecturas suponen para la construcción de la identidad individual y colectiva (políticas, nacionales, sociales, etc.). Como ámbito específico de la geografía literaria, la geopoética estudia el espacio que dibujan las ficciones sobre el espacio real embelleciéndolo, como hace un paisajista al humanizar, embellecer, domesticar el paisaje, y darle una forma.

Desde esta perspectiva se comprendió el proyecto DLLHO_19 «Diseño de un Legendario Hispánico del siglo XIX accesible online» cuyo objetivo era poner a la disposición del gran público un repertorio que aglutinase los textos literarios más valiosos de este siglo de oro de la leyenda literaria, preparados para la comprensión de lector moderno mediante anotación y bibliografía. Lo que pretendía esta plataforma era la potenciación del repertorio y el uso creativo de los lectores-prosumidores del turismo cultural y literario. Mediante la geolocalización estos textos podrían ser consultados in situ, acrecentando de este modo las cualidades explicativas, etiológicas, históricas

\footnotetext{
${ }^{14}$ Como bibliografía de referencia puede consultarse D. Pocock, «Geographical fieldwork: an experiential perspective», Geography: Journal of the Geographical Association, 68 (4), 1983, p. 319 y J. D. Porteous, «Smellscape», Progress in Physical Geography, 9 (3), 1985, pp. 356-378.
} 
o fundacionales a las que aspiraba el texto. Con este tipo de lectura se favorecía la experiencia subjetiva y emocional del lector / viajero.

Un ligero repaso por las webs destinadas al turismo cultural y estrechamente vinculadas a los BIC demuestra la generalización de rutas y paseos guiados por las ciudades para conocer las leyendas del lugar. En muchos casos estas visitas se transforman en una performance teatral, con participación del público, sobre un guión mínimamente dispuesto, y su objetivo es reforzar el papel informativo del guía turístico con un espectáculo de amenidad. El guión enlaza varias leyendas someramente apuntadas que protagonizan unos pocos personajes históricos o ficticios.

La revisión de estos espectáculos, y de las páginas en las que instituciones oficiales, empresas turísticas o blogueros referían las leyendas de lugar, ha puesto de manifiesto, en su mayoría, un conjunto de escasa calidad literaria y rigor histórico. Por otra parte, tanto las empresas de visitas teatralizadas como las páginas de leyendas evidencian el desconocimiento de tradiciones que en el pasado dieron lugar a trayectorias de creación literaria. En este contexto, el proyecto DLLHO_19, se propuso favorecer el acceso a textos literarios que pudiesen servir de alimento a los dos tipos de usos culturales detallados: la visita teatralizada y la antología legendaria por lugares.

La elección del siglo XIX como fuente de estas versiones vino determinada por la singularidad que el género obtuvo en este momento, en que la leyenda fue acuñada por los poetas y narradores como nuevo género literario. Desde el segundo tercio de siglo se produjo en toda la península un fenómeno de promoción de la leyenda literaria por razones variadas: desde la nostalgia romántica de los siglos medievales al entusiasmo regional y la intención legitimadora de los nacionalismos gallego y catalán, etc. que estuvieron en el origen de la promoción del movimiento floralista. Sobre la base de tradiciones orales, recuerdos del lugar, o motivos del imaginario popular se confeccionaron muchos textos, íntimamente relacionados con la explicación de espacios naturales y culturales, que tuvieron su repercusión en la configuración del imaginario de los viajeros (españoles o extranjeros ${ }^{15}$ ). Por sus condiciones formales, corta extensión, motivos tipificados y demanda de lectores, las revistas y periódicos literarios fueron el soporte predilecto de difusión de la leyenda literaria. En estas publicaciones de diversa procedencia, confeccionaron textos de este tipo autores literarios, más o menos consagrados, eruditos, colaboradores ocasionales y lectores, además de los redactores de las cabeceras. Este tipo de texto sobrevivió a través de

\footnotetext{
${ }^{15}$ Entre ellos Washington Irving, que visitó la localización de la cueva de Hércules en Toledo, bajo la iglesia de S. Ginés, en 1826 y reprodujo la historia en los capítulos VI y VII de las Legends of the conquest of Spain, London, John Murray, 1836.
} 
todas las estéticas, romántica, realista, modernista, y sostuvo pretensiones políticas de signos contrapuestos.

En relación con la leyenda, la perspectiva conservacionista fue el modo de afrontar la recuperación de las tradiciones por parte de los primeros estudiosos del folklore en nuestro país. Después del trabajo de humanistas como Hernán Núñez el Pinciano o Juan de Mal Lara en el siglo XVI, que recogieron cuentecillos y refranes de informadores orales en busca de la filosofía vulgar expresada en las producciones del pueblo $^{16}$, en el siglo xIx, por influjo de la devoción nacionalista alemana (Herder, Grimm, Naubert, Tieck) y el ejemplo de escritores como Walter Scott o René Chateaubriand, se reinició en nuestro país el coleccionismo de textos de literatura popular. Primeramente, fueron rescatados los romances, por Jovellanos, Nicolás Bölh de Faber, y de modo decisivo Agustín Durán, pero también serán dinamizados en el uso cultural como refleja la moda del romance literario en autores Juan Arolas, el duque de Rivas, etc. (tras los pasos de lo realizado por Lope, Quevedo, Góngora y tantos autores del siglo de Oro). La recuperación del cuento popular y de la leyenda contó con la labor de figuras insignes como Fernán Caballero, y en el uso cultural del cuento folklórico como género literario con autores como Antonio Trueba, Luis Coloma, según ha estudiado Montserrat Amores ${ }^{17}$. También las leyendas nacionales o del país, catalogadas en una serie de rótulos: nacionales, históricas, religiosas, caballerescas, recibieron un tratamiento novedoso en la obra de Gertrudis Gómez de Avellaneda, José Zorrilla, Bécquer, Manuel Fernández y González, bien en la lírica, la novela o el teatro. La labor conjunta de todos estos escritores trató de preservar de la desaparición absoluta las tradiciones, recuerdos, modos de vida que solo contaban con el registro oral para su supervivencia, y en muchas ocasiones, en lenguas no oficiales, como el gallego, vasco o catalán); y no raramente esta actividad coleccionista fue promovida también por movimientos políticos de orientación nacionalista o regionalista. Pueden recordarse las leyendas catalanas recogidas por Pablo Piferrer, las muchas leyendas de toda España incluidas en libros de viajes por Víctor Balaguer y Francisco de Paula Mellado,

\footnotetext{
${ }^{16}$ Y muchos otros eruditos, como Lorenzo Palmireno, Gonzalo de Correas, Sebastián de Covarrubias, Luis Pinelo, Luis Zapata, Juan Farfán, que prestaron atención a los refranes, proverbios, cuentecillos populares. En las centurias siguientes, se aborda el proceso de la literaturización de productos populares, como el romance, en los romances literarios de poetas como Lope, Góngora y muchos otros escritores y la utilización en la narrativa y el teatro del cuentecillo popular, y los temas legendarios.

${ }^{17}$ Entre los recopiladores cabe citar a Juan Nicolás Bölh de Faber con su Floresta de rimas antiguas castellanas, (1821); Agustín Durán, en su Romancero general o colección de romances castellanos anteriores al siglo XVIII, (1828-1832), Fernán Caballero, que edita sus seis volúmenes de tradiciones populares (cantos, consejas, leyendas y tradiciones populares e infantiles) entre 1859 y 1877 . Y fundamentalmente la Biblioteca de las Tradiciones populares españolas, Francisco Álvarez y Ca ${ }^{\mathrm{a}}, 1883$, promovida por Antonio Machado y Álvarez (Demófilo). Para consultar los ejemplos de escritores que remodelaron literariamente el cuento popular en el siglo XIX es imprescindible el catálogo de Montserrat Amores, Catálogo de cuentos folclóricos reelaborados por escritores del siglo XIX, vol. 27, Editorial CSIC-SIC Press, 1997.
} 
o coleccionadas por eruditos locales ${ }^{18}$. El mismo objetivo guiaba al costumbrismo romántico con su retrato de los «oficios en trance de desaparición», «tipos pintorescos», característicos de un momento y lugar, pero a punto de perderse. Pero, según se acaba de indicar, no estuvo fuera del objetivo de los escritores del siglo XIX la dinamización del patrimonio legendario dado que estos autores no sólo transcribieron tradiciones sino que dieron lugar a género literario histórico de «la leyenda poética», y utilizaron procesos de transferencia e intermedialidad al servirse de las leyendas en nuevos soportes como el teatro (lírico, cómico, dramático); la pintura, además del empleo del legendario en libros de viajes, novela histórica o poesía narrativa. En realidad, podría hablarse del género de la «leyenda dramática» también, en la que consecharon triunfos José de Echegaray, Joaquín Dicenta, Manuel del Palacio, Mariano Catalina o Manuel Cano y Cueto.

Por su variedad de registros, calidad literaria en la mayoría de los casos, perfil de sus autores, muchos de ellos historiadores y que por tanto ofrecían una versión fidedigna de la leyenda, y por su indudable comprensión dinámica del patrimonio literario, consideramos que la leyenda literaria del XIX constituía un material de gran valor para una diversidad de usos culturales ${ }^{19}$ del patrimonio literario.

Ya que la leyenda literaria fue un género que sobrevivió durante todo el siglo XIX y fue amoldándose a las exigencias de los diferentes movimientos estéticos estos textos aportan notable interés para la consideración del romanticismo, costumbrismo, realismo, simbolismo, etc. Como ejemplos tomados del repertorio https://www. descubreleyendas.es podemos seguir las aplicaciones dadas a la etiqueta «romántico» a través de los textos, que es aplicada tanto a un paisaje («Pagaraisla en Campomanes») como un edificio («San Juan de la Peña») o a una escena que podría servir de inspiración a un pintor romántico («La virgen de la montaña»). Y por su interés en esta valoración de la distancia de estilos y puntos de vista en la escritura transcribimos esta reflexión de Víctor Balaguer en su libro A granel, en que el autor contrasta estilos de escritura a propósito de la composición de una leyenda:

Publico estas impresiones tales como fueron pensadas y escritas, que no quiero borrarles su color de época, en forma de leyenda romántica, con todos los sellos, arreos, menesteres

\footnotetext{
${ }^{18}$ Recopiladas según provincias o comarcas, por ejemplo, las leyendas granadinas, coleccionadas y vertidas al molde literario en varios tomos por J. Afán de Ribera, Luis Montes, o J. Soler de la Fuente.; las tradiciones sevillanas, que recoge Manuel Chaves y Manuel Cano y Cueto; las leyendas de Toledo de Juan Moraleda o Eugenio Olavarría, de Ávila como las Tradiciones de Valentín Picatoste. O bien las colecciones generalistas: entre ellas las de Luciano García del Real, José Doménech, Luis Escudero y Peroso, etc. Las leyendas también pueden ser coleccionadas según criterios temáticos: leyendas religiosas, por ejemplo, como las de Anna Valldaura, Julio Bernal y Soriano, o Leopoldo Martínez Padín y Muñoz Maldonado. En ocasiones se coleccionan leyendas en torno a un edificio (El Escorial, según hace Muñoz Maldonado, o los conventos famosos, en la práctica de Víctor Balaguer).

${ }^{19}$ Por usos culturales entendemos la representación cultural de un elemento patrimonial, en conexión con empresas culturales, de cara a su rentabilidad desde un punto de vista educativo, social, económico.
} 
y atributos de lugar y tiempo. Me limito solo a corregir algún error de fondo y a enmendar descuidos de forma.

Acaso estas páginas parezcan fuera de uso; que no se escribía en aquellas- 178 épocas como ahora. Se dejaba entonces campear libre la fantasía, que hoy se reprime; se perseguían y se tenían ideales que hoy ni se persiguen ni se sienten, y se procuraba dar amenidad al escrito, lo cual hoy no se juzga muy necesario.

Pudo estar equivocado, no digo que no, la juventud de aquella época, pero también creo que puede estarlo la presente ${ }^{20}$.

El repertorio presenta textos de interés para la investigación sobre la tradición popular, las identidades nacionales y las geografías literarias. Para los estudiosos del imaginario, un legendario de acceso digital y con opción multicanal permite establecer analogías y relaciones significativas en relación con temas, motivos, personajes, lugares, y trazar rutas e itinerarios.

Tomando como ejemplo el Rey D. Pedro de Castilla el repertorio descubreleyendas.es permite dibujar su movimiento a través de localidades y ciudades, situar sus lugares de residencia o fijar el lugar de las anécdotas más famosas. En Sevilla, el rey confía el Ayuntamiento a un diligente escribano de la familia de los Pineda, se ajusticia a sí mismo, simbólicamente, colgando una cabeza en la calle donde dio muerte a un rival de sus amores («Justicias del rey D. Pedro»), o no quiere faltar a la fama de que cumple sus promesas, aunque en este caso es una promesa que nunca hizo, e indulta a un condenado a muerte («El caso del condenado a muerte»). En Madrid, el rey D. Pedro I de Castilla interviene personalmente en el esclarecimiento y resolución de una historia protagonizada por Iván Ramírez. El monarca imparte justicia ante la situación de este personaje que es engañado y agredido por un pariente que intenta matarle para quedarse una herencia que corresponde legítimamente a su hijo («El bodegón de la cadena»), entre otros ejemplos.

Por otra parte, las posibilidades de acumulación que permite la herramienta tecnológica podrán favorecer la asociación de versiones de un mismo tema legendario y de su posible comparación. El resultado es la ordenación de episodios dentro de un tema legendario, las diferentes versiones en función de autores y tendencias ideológicas, y el examen de los meta-textos y glosas añadidos a la interpretación de la leyenda. Tomando como ejemplo la desgracia de los hermanos Carvajal, ejecutados por orden de Fernando IV, la plataforma favorece la comprensión y división de los episodios: la enemistad de los hermanos Carvajal con Juan de Benavides, la muerte del favorito (de la que son acusados los Carvajal, aunque no hay pruebas convincentes), la ejecución desde la Peña de Martos, la enfermedad y muerte del rey poco después, que fue interpretada como un castigo divino. Es fácil establecer comparaciones entre los

${ }^{20}$ V. Balaguer, San Juan de la Peña, A Granel, 1896, p. 111. 
autores del repertorio que se ocupan de la leyenda, Telesforo Trueba, Ángel Gálvez, Ramón Ortega Frías, Isabel Camps Arredondo y Dionisio Ibarlucea. Ortega Frías hace la narración completa, y Gálvez y Camps se fijan en la ejecución y la subsiguiente muerte del rey. La plataforma facilita la particularización de los materiales; es significativo en este ejemplo, que solo Camps, poetisa jienense sea la única que hace mención al hito de «la cruz del lloro». Ortega Frías tiende a novelar la leyenda y razonar las causas por las que los Carvajal fueron acusados, un episodio amoroso y un falso testimonio. Dionisio Ibarlucea reescribe la historia en una publicación para niños (El amante de la infancia, 1866) y destaca por ello la lealtad de los Carvajal al rey, que no eluden la posible salvación de la muerte si colaboran en una conspiración contra Fernando IV. Así pues, con la lectura simultánea de las versiones de una misma leyenda se facilita el análisis del pensamiento político y social de creadores y de lectores, al tomar en cuenta los lugares de publicación.

Del mismo modo, la recopilación y conexión hipertextual favorece la interrelación de disciplinas, y permite llegar a nuevas conclusiones interesantes para la Historia del Periodismo, y de la bibliografía general, en lo relativo a autores y géneros. Como ejemplo sirven los textos del repertorio firmados por Francisco Fernández Villabrille, autoridad reconocida por el Diccionario Biográfico Español de la Real Academia de la Historia, dbe.rah/ como «uno de los autores españoles más prolíficos en cuanto hace a temas de educación tanto para sordos como para ciegos, además de escribir sobre los temas más variados, tales como educación o historia». Podrían añadirse noticias sobre su labor literaria en el Museo de las Familias con la publicación de leyendas literarias (1846 y 1849) y en la revista Siglo XIX (en 1837), tal vez a raíz de su participación en la obra colectiva, Diccionario Universal de Historia y Geografía (F.P. Mellado, 8 vol.1846), o sus poemas, entre los que destaca «Descubrimiento del Nuevo Mundo», Colón.

Otro aspecto que puede destacar el repertorio es el testimonio de hitos desaparecidos, o de significados previos otorgados a un espacio. El ejemplo en este caso es el «Pozo de Funeres», actualmente ligado a un siniestro episodio de la guerra civil en 1936, pero del que antes se contaba la leyenda de «La fuente del collar», como recuerda Eladio Jove ${ }^{21}$.

Finalmente, y enlazando con lo planteado al principio de este epígrafe, un repertorio de estas características puede servir de fuente documental en la creación de nuevos productos, servicios, procesos, de desarrollo económico; ya que facilita el acceso de las empresas (turísticas, grupos teatrales, productores audiovisuales) a textos poco conocidos o utilizados.

${ }^{21}$ E. Jove, La fuente del collar, disponible en: https://www.descubreleyendas.es/Info/Consultas. aspx?IdLeyenda $=19$ 
La conclusión de estas reflexiones es la necesidad de continuar apoyando las iniciativas de digitalización de patrimonio literario sostenidas en nuestro país por las actuaciones gubernamentales y las fundaciones privadas, de tanta solidez y consistencia ya, y que según manifiestan nuevos proyectos, como el que hemos descrito aquí, han sido el punto de partida para posibilidades de dinamización del patrimonio literario.

\section{BibLIOGRAFÍA}

Alvar, C., El rey Arturo y su mundo: diccionario de mitología artúrica, Madrid, Alianza, 1991.

AfÁn de Ribera, A. J., Cosas de Granada: leyendas y cuadros de antiguas y modernas costumbres granadinas, Granada, [s.n.], 1889.

, Del Veleta a Sierra Elvira: leyendas, cuentos y Tradiciones granadinas, Granada [s.n.], 1893.

, Entre Beiro y Dauro, Granada, Vda. e Hijos de P. V. Sabatel, 1898.

, Leyendas y Tradiciones, Granada, Imp. de La Lealtad, a cargo de J. G. Garrido, 1887.

Los días del Albaicín: Tradiciones, leyendas y cuentos granadinos, Granada, [s.n.], 1886.

AMores, M., Catálogo de cuentos folclóricos reelaborados por escritores del siglo XIX, Vol. 27, Madrid, Editorial CSIC-SIC Press, 1997.

BALAGUER, V., «San Juan de la Peña», Los frailes y sus conventos: su historia, su descripción, sus Tradiciones, sus costumbres, su importancia, [Barcelona] Llorens Hermanos, 1851.

, El Monasterio de Piedra. Su historia, sus valles, sus cascadas, sus grutas, sus Tradiciones y leyendas, Madrid, F. Cao y D. de Val, 1880.

, Historias y leyendas, Madrid, Imp. De la Viuda de M. Minuesa de los Ríos, 1889. , A granel: libro de pasatiempo y deporte, Madrid, El Progresso Editorial, 1896.

, Al pie de la encina: historias, Tradiciones y recuerdos, Madrid, Minuesa de los Ríos, 1898.

Bataller Catalá, A., «La ruta literaria como actividad universitaria vinculada al territorio y al patrimonio». Disponible en: https://www.uv.es/asabranca/ encontre/bataller.pdf [Consultado: 23-12-2018]

BERNAL y SORIANO, J. Tradiciones histórico-religiosas de todos los pueblos del arzobispado de Zaragoza, en el Establecimiento Tipográfico de Mariano Salas (Zaragoza), 1880.

Bölh de FAber, C. (Fernán Caballero), Cuentos y poesías andaluces coleccionados, Sevilla, Mercantil, 1859.

BöLH DE FABER, N., Floresta de rimas antiguas castellanas, Hamburgo, F. Perthes, 1827-43. 
Pilar Vega Rodríguez

Bonnemaison, J., Lasseur, M., \& ThiBault, C., La Géographie culturelle: cours de l'université Paris IV-Sorbonne 1994-1997, 2000.

Brosseau, M., \& CAMBRON, M., «Entre géographie et littérature: frontières et perspectives dialogiques», Recherches sociographiques, 44(3), 2003, pp. 525-547. Disponible en: https://www.erudit.org/en/journals/rs/2003-v44-n3-rs727/008205ar/ abstract/ [Consultado: 25 de febrero 2019].

CAMPS, J., \& Viladegut, M., «Les rutes literàries com a introducció a la geografia artística dels escriptors», en Jornada sobre Literatura i Ensenyament, 2009. Disponible en: http://www.catedramariustorres.udl.cat/activitats/jornades/jorn_5t.pdf [Consultado: 25 de febrero 2019].

Cano y Cueto, M., Leyendas y Tradiciones de Sevilla, Sevilla, Francisco Álvarez y Ca , 1875.

Chaves, M., Páginas sevillanas: sucesos históricos, personajes célebres, monumentos notables. Tradiciones populares, cuentos viejos, leyendas y curiosidades, Sevilla, Imp. de E. Rasco, 1894.

Crang, M., \& Thrift, N. J. (eds.), Thinking space, 9 (2000).

Domenech, J., El pasatiempo: colección de novelas, cuentos y leyendas españolas, Valencia, imp. de la Opinión, 1862.

Dosso, R., «Paisaje, turismo y desarrollo. Contribuciones conceptuales para un desarrollo sustentable», Comunicación presentada en IV Congreso Latinoamericano de Investigación Turística, Montevideo [URY], 22-24 septiembre, 2010.

DurÁN, A., Romancero general o colección de romances castellanos anteriores al siglo XVIII, Madrid, M. Rivadeneyra, 1849.

Escudero y Perosso, L., Colección de leyendas españolas, Sevilla, Imprenta y Litografía de El Porvenir, 1865.

Fernández Herrero, M., Los mil y un cuentos: colección de leyendas, novelas, anécdotas y tradiciones en prosa y verso de escritores españoles antiguos y modernos, Madrid, Gabriel Díaz y Compañía, 1870.

García Canclini, N., «Los usos sociales del Patrimonio Cultural», en E. Aguilar Criado, Patrimonio Etnológico. Nuevas perspectivas de Estudio, Consejería de CulturaJunta de Andalucía, 1999, pp. 16-33.

García ReAL, L., Tradiciones y leyendas españolas, Barcelona, Tasso, 1899.

Jove, E. «La fuente del collar», La Opinión: periódico de intereses morales y materiales [Año III, Número 241 - 14-12-1879], pp. 2-3; [Año III, Número 242 - 18-12-1879], pp.23; [Año III, Número 243- 21-12-1879], pp. 2-3. Disponibles en: https:/ / www. descubreleyendas.es/Info/Consultas.aspx?IdLeyenda=19 [Consultado: 25 de febrero 2019].

IRVING, W. Legends of the conquest of Spain, London, John Murray, 1836. 
Martínez Garate, L., \& Ayerra, H. A., Conferencia Patrimonio: ¿un concepto en crisis? España, 2006, Disponible en: http:/ / nabarralde.com [Consultado: 2 de marzo 2006].

Martos Núñez, E. \& Martos García, A. E., «Las leyendas regionales como intangibles territoriales», 2015. Disponible en: http:/ / dehesa.unex.es/handle/10662/7443 [Consultado: 25 de febrero 2019].

Moraleda y Esteban, J., Leyendas históricas de Toledo, Toledo, Librería y Encuadernación de Menor Hermanos, 1892.

Muñoz Maldonado, J. (conde de Fabraquer), Historia, Tradiciones y leyendas de las imágenes de la Virgen aparecidas en España, Madrid, J.J. Martínez, 1861. , Los Misterios del Escorial: historia, leyenda, Tradiciones: famosas hazañas, tenebrosos crimenes, amores, Barcelona, Editorial de Espasa Hermanos, 1880.

Ortega VAlCÁRCEL, J., «El patrimonio territorial: el territorio como recurso cultural y económico», Ciudades, 04 (1998), pp. 31-48.

Picatoste, Valentín., Tradiciones de Ávila, Madrid, Miguel Romero (impresor), 1888.

Pillet Capdepón, F., La geografía y las distintas acepciones del espacio geográfico, 2004.

, «El paisaje literario y su relación con el turismo cultural», Cuadernos de turismo, 33 (2014), pp. 297-309.

Poсоск, D., «Geographical fieldwork: an experiential perspective», Geography: Journal of the Geographical Association, 68, 4 (1983), p.319.

Porteous, J. D., «Smellscape», Progress in Physical Geography, 9,3 (1985), pp. 356-378.

Silva Pérez, R., \& Fernández Salinas, V., «El patrimonio y el territorio como activos para el desarrollo desde la perspectiva del ocio y del turismo», Investigaciones Geográficas, 46, mayo-agosto (2008), pp. 69-88. Disponible en: http://rua. ua.es/dspace/handle/10045/14607 [Consultado: 25 de febrero 2019].

SoldeVILA, Ll., "Geografia literària dels països catalans: la gènesi d'un projecte'a», Literatura i paisatge, Tarragona, 2009. Disponible en: https://www. yumpu. com/es/document/view / 13084056/literatura-i-paisatge-a-cura-definaangles-2009-apellc [Consultado: 25 de febrero 2019].

SOLER De LA Fuente, J., Tradiciones granadinas, Granada, Manuel Sanz, 1849.

UNESCO, Convención para la salvaguarda del Patrimonio cultural inmaterial, 2004. Disponible en: http:/ / portal.unesco.org [Consultado: 25 de febrero 2019].

Valldaura, A., Tradicións religiosas a Catalunya, Estampa de J. Roca.1877.

VVAA., Tradiciones populares españolas, Francisco Álvarez y Ca ${ }^{\mathrm{a}}, 1883$, promovida por Antonio Machado y Álvarez (Demófilo). 